\title{
APPLICATION OF SIMULATION METHODS FOR STUDY ON AVAILABILITY OF ONE-AISLE MACHINE ORDER PICKING PROCESS
}

The main aim of the paper is the analysis of simulation model reflecting selected in-warehouse logistics processes in the aspect of their availability. For this purpose, one-aisle machine picking problem with use of a stochastic random simulation is studied, with a special focus on reliability of the system to disturbances and maintenance scheduling. The methodology in the research consists of classic measures of reliability. The model is designed in order to analyze availability of selected parameters of randomly generated order picking process. One of key-results of the paper is answer for question if a mean time to failure can be treated as a value of time when the first failure in the system occurs. A summary of the contribution includes discussion and the perspectives for further research in the subject matter.

Keywords: availability, MTTR, MTBF, MTTF, failure rate, failure frequency, warehouse

\section{Introduction}

The order picking (later: OP) process is deliberated as one of the most important among processes in internal logistics. It is believed as such because this process is the most labor consuming one and it determines the level of service experienced by the down-stream customers [1]. Moreover, it engages most of resources of all processes realized in logistics facilities (that aspect is connected to labor consuming), which is confirmed in [2]. In addition, this process is considered to be the most time consuming [3-4]. All these aspects aim to find out that it is highly cost-consuming process. Authors of [5] estimated OP cost - they stated that the cost incurred during OP processes is from $55 \%$ to $75 \%$ of total cost for all logistics processes in warehouses (it is also mentioned e.g. in [6-7]). OP process consists of roughly three phases. The first one is travel to the predefined storage location which is non-value-adding according to [1], the second one is search of the exact location wanted. This phase can be significant while picking of small parts, and it is considered also as non-value-adding phase. The third phase is connected to three actions: reach, take, and deliver to the appropriate in/out spot. This is a value-added and the most resistant to automation activity.

As it was mentioned in many references, the scope of scientific elaborations on OP processes is very broad. The authors deal with e.g.: strategies used to achieve efficient OP process (e.g.: [8-10]), cost estimation based on highly detailed and hierarchical analytical or numerical models, and reduction of processes duration (or indirectly, by reduction of traveled distance between picking points, as in [3, 11-12]. Many other authors attempted to reduce OP process time, as in: [7, 13-14].

In order to achieve as much as realistic simulation model as possible, during its building some events, which potentially disrupt a regular material-flow should be included. This kind of events can be implemented accurately or randomly. Retooling, maintenance times, accidents, machine failures and many other kinds of disturbances can be included in simulation to make it firstly more realistic, more adequate to real logistics facility, and secondly to execute what-if analyses in order to be ready for unpredicted failures or "catastrophes", which might took place in a logistics facility implemented into simulation model. In many simulation software there are at least two options for failures modeling [15]. The first one is using statistical distribution and the second one is application of certain areas based on reliability theory. In the model used for this study second option was implemented. By the way, paraphrasing of "failure" meaning given in [16], it is understood in the paper as a unit/machine/mean of transport/device which has not met user/customer/operator requirements in some way during its functioning.

Taking into consideration all the above statements, a model for OP analyses in one aisle in OP area was developed (this one aisle is operated by one automated machine: an automated storage and retrieval system AS/RS). The main objective of this model is to obtain a sequence of any number (by default, one hundred) of durations of $\mathrm{OP}$ process taking place within $\mathrm{OP}$ area in a hypothetical

\footnotetext{
Mariusz Kostrzewski ${ }^{1, *}$, Jozef Gnap ${ }^{2}$, Pavol Varjan ${ }^{3}$, Marek Likos $^{4}$

${ }^{1}$ Division of Construction Fundamentals of Transport Equipment, Faculty of Transport, Warsaw University of Technology, Poland ${ }^{2}$ Department of Road and Urban Transport, Faculty of Operation and Economics of Transport and Communications, University of Zilina, Slovakia

${ }^{3}$ Office of the Presov Self-governing Region, Presov, Slovakia

${ }^{4}$ Faculty of Transport, Warsaw University of Technology, Poland

*E-mail of corresponding author: mariusz.kostrzewski@pw.edu.pl
} 
warehouse. This paper is connected to the simulation model presented in [17] (briefly described in third section of the paper, the one connected to methodology). For this paper, the model would be analyzed in the context of the accessibility of machine contributing to OP process operation and in the context of other concepts related to mentioned accessibility. Therefore, it can be assumed that the following parameters are analyzed with use of the model: availability, mean time to failure, mean time between failures, mean downtime, mean time to diagnose, mean time to recovery, failure rate, etc. One of the aims of the article is to answer the following research question. Can the simulated times up to the first failure of the means of transport and the times obtained on the basis of calculated statistical values for selected accessibility characteristics be treated identically? In other words, can the mean time to failure, calculated from the generalized mean time to failure equation, be treated as the value of time when the first failure in the model occurs? It seems to be important question, especially that a wide range of innovative concepts make transport systems (and equipment) more efficient and competitive [18], therefore these systems and equipment need to be analyzed adequately.

\section{Literature review}

Several equations for assessing availability of agents (e.g. means of transport) taking part in a process can be found in literature. These equations are based on available data on damage to components over time. These data are used in order to create an availability model, which is designed to reproduce as faithfully as possible an operating process of a machine/vehicle, etc. However, when hypothetical facilities are analyzed, no historical data is connected to any failures in the process. For this reason, a simulation modeling may be implemented for analyses. Simplifications are adopted for such models, which are described in methodology section.

The origin of using mean time between failures (MTBF), mean time to recovery (MTTR) was in computer science and information technology and later in operational management. At first, it was used in order to determine the durability of hard drives. Author of [14] described core principles of reliability in software engineering.

As Authors of [19] mentioned, most of companies implement lean management for their operational realization. One of the methods, which is connected to lean management is Total Productive Maintenance (TPM). MTBF, MTTF, MTTR and OEE (Overall Equipment Effectiveness) are some of many key performance indicators (KPIs) allowing to analyze disturbances and failure rates of production processes. In the mentioned paper, it is used for windscreen wipers production, assembly process and internal transport analyses. Meanwhile, Authors of [20] use the term of mean time between overhaul furthermore - since this parameter is used mostly for engines, it is not considered here.
Research results on this subject in the context of logistics (and especially intralogistics) are published much less frequently. Authors of [21] used chosen KPIs in order to analyze the system composed of a machine, a warehouse, a vehicle and customers. Authors realized it in order to choose a suitable vehicle type according to different costs of this system taking into consideration MTTR and MTBF. Authors of [22] prepared a multicriteria rating of the batch process method, including four KPIs as technological aspects evaluation in this method. KPIs were also used in [23] in order to reduce intralogistics costs of spare parts and semi-finished products while implementation of digitization in maintenance. Authors of [24] used chosen KPIs in order to analyze buffers next to assembly lines system with material handling. However, several publications touched devices availability analyses for internal logistics, these were hardly connected to treat it as the main subject matter.

\section{Methodology, research conditions and assumptions}

The methodology consists of several parts. At first, it involves data compilation and pre-processing (despite the model consists of hypothetical data, these must meet requirements related to the real-world facilities). Secondly, it involves data exploration (mostly, statistics exploration). Third part includes developing and experimenting with the simulation model, while the last part entails evaluation and interpretation of results of the experiments.

In modeling theory, the category of models, which selected parameters can be described by random variables, distinguishes deterministic and stochastic models. In a deterministic model none of random variables are implemented. Stochastic model contains at least one variable of random kind [17, 25-26]. The model considered in this paper is stochastic one.

The main assumptions of this simulation model are connected to the fact that it realizes a sequence of randomly matched picking lists. The particular picking list is described by two parameters. The first one is the number of lines in each picking list that correspond to assortment of products to be picked during certain order realization. The second parameter is the quantities of items of a certain product to pick from a certain shelf in OP area. The number of lines in each picking list (of a $j$-th element in the sample for $k$-th experiment) reaches the scope of $w(j, k)=\{1, \ldots, 10\}$, and the quantities of $i$ items to pick (per line in a $k$-th experiment) are within the scope of $p(i, j, k)=\{1, \ldots, 10\}$. Picking lists are generated as a result of initiation of adequate procedure with pseudorandom number generator (PRGN) included in the simulation model, and this PRGN is defined and constructed by first author based on the logistics map. It starts from random numbers uniformly distributed between 0 and 1 , generated by a suitable standard random number generator $\left(p^{*}(1,1, k)\right.$ in Equation (1)), and obtains the sizes of items to be picked using bifurcation of the logistics map (value 4 in Equation (1) ensures that the data structure is 
chaotic), inspired by [27] (in order to obtain integer values of $p(i, j, k)$, a multiplier by 10 is entered). A picking list in the model is a series of orders not known in advance that have to be served one after another. More details and PRGN verification are given in [28].

$$
\begin{aligned}
& p(i, j, k)=\left[10 \cdot 4 \cdot\left(1-\left(p^{*}(i-1, j-1, k-1)\right)\right) .\right. \\
& \left.\cdot p^{*}(i-1, j-1, k-1)\right] \\
& p^{*}(1,1, k) \in(0 ; 1\rangle
\end{aligned}
$$

In order to generate picking lists, logistic differential equation is used in the model. It ensures gaining PRGN values which are more random than in the case of using simply probability distribution. Empirical research with use of simulation model proved that in the case of using chosen probability distribution results were repeatable in the case of $80 \%$ of experiments [17]. In order to exclude repetition, logistic differential equation was introduced.

The simulation model allows to study several parameters connected to reliability and availability of means of transport used in examined logistics facility. Mentioned parameters are directly connected to reliability or having an impact on it (indirect impact). These parameters are: processing time, recovery time, cycle time, capacity, mean time to repair, availability. Moreover, the group of parameters can be broadened by another ones, which might be useful in a study of reliability and availability of machines and means of transport that are not unambiguously defined in the software and require to be redefined in simulation model. These parameters, not exclusively, are mean time to failure (MTTF), mean time between failures (MTBF), estimated percentage of simulation time during which a mean of transport failure may occur $(f(k)$; this is parameter similar to unavailability - the difference is that $f(k)$ is stochastic parameter, which value is drawn on the basis of PRGN built into the software and its value in relation to availability $\eta_{T}$ is characterized by the relation $f(k)<1-\eta_{T}$, whereas unavailability $\overline{\eta_{T}}$ is characterized by the following relation $\overline{\eta_{T}}=1-\eta_{T}$.

The simulation model has been satisfactory verified before and verification proved that the difference between the results of the simulation model and the analytical model is at acceptable level of 3.5\%. The model was not validated, since it is hypothetical warehouse.

According to [29], the availability is equal to the probability of a unit/machine/mean of transport when it is operated correctly and without any malfunctions. It is determined by Equation (2), where: $\eta_{T}$ is parameter of availability (unitless parameter), $T$ is total operating time [min] and $T_{\text {out }}$ is a sum of individual periods of downtime [min].

$\eta_{T}=\left(T-T_{\text {out }}\right) / T$

According to [29], mean time to repair (known also as mean time to restore, mean time to recovery as in [12] or mean downtime, [min]) MTTR is total downtime $T_{\text {out }}$ [min] divided by the numbers of malfunctions $n_{\text {out }}$ (unitless parameter) given according to Equation (3).

$M T T R=T_{\text {out }} / n_{\text {out }}$

MTBF is mean time between failures or disruptions in the operation of a product, process, procedure, design, machine, unit, mean of transport. Mean time between failures assumes that a product - or any other mentioned entity - can be repaired, and a product can then resume its normal operations [30]. According to [29], the mean time between failures $M T B F$ is given according to Equation (4) in [min].

$M T B F=\left(T-T_{\text {out }}\right) / n_{\text {out }}$

And based on Equations (2)-(4), the availability can be expressed by MTTR and MTBF parameters, as in Equation (5) - as such is exposed also in [15].

$\eta_{T}=M T B F /(M T B F+M T T R)$

MTTF (Mean Time To Failure) determines the average operating time of a device from the beginning of its operation or from its last repair to the first failure [31]. This parameter is particularly important for systems in which single operations last a long time - small values of MTTF significantly reduces a probability of correct completion of a single operation. In a lot of design, components and devices, a value of MTTF is especially near to a value of MTBF (Mean Time Between Failures). Typically, MTBF is slightly longer than MTTF [31]. MTTF should be used for non-repairable items, however it has been studied here in order to examine the interdependence of different parameters of this type.

In the paper [32] and book [33], the availability is given as Equation (6).

$\eta_{T}=\operatorname{MTTF} /(M T T F+M T T R)=M T T F / M T B F(6)$

Equation (5) is used in the case, when it is dealing with impact of a repairable element on availability of a system (refurbishing/remanufacture is not understood as repair, but rather replacement). And the Equation (6) is used when it is dealing with impact of a one-off/non-repairable element on availability of a system, in which it operates (an element could be refurbished/remanufactured) [30]. The simulation model is assumed to deal with a situation, where replace parts in equipment subject to failure is possible - therefore Equation (5) is used.

Failure rate $\left[\mathrm{min}^{-1}\right]$ is the total number of detected defects divided by the total number of samples observed, and according to [32] is as given in Equation (7).

$\mu=1 / M T B F$

Failure frequency (unitless parameter), according to [32], is given as in Equation (8). 
Table 1 Summary of the parameters for assessing the availability of AS/RS

\begin{tabular}{|c|c|c|c|c|c|c|c|c|c|}
\hline $\mathrm{k}$ & $\begin{array}{r}f(k) \\
{[\%]}\end{array}$ & $\begin{array}{c}\operatorname{MTTR}(k) \\
{[\mathrm{min}]}\end{array}$ & $\begin{array}{r}\eta_{T} \\
{[-]}\end{array}$ & $\begin{array}{l}\text { Operating } \\
\text { time } \\
\text { [min] }\end{array}$ & $\begin{array}{c}\operatorname{MTTF}(k) \\
{[\mathrm{min}]}\end{array}$ & $\begin{array}{c}\operatorname{MTBF}(k) \\
{[\mathrm{min}]}\end{array}$ & $\begin{array}{l}\mu(k) \\
{\left[\min ^{-1}\right]}\end{array}$ & Failed [\%] & $\begin{array}{c}\tau(k) \\
{[-]}\end{array}$ \\
\hline 1 & 10 & 1 & 90 & 1683.94 & 8.10 & 9 & 0.11111 & 10.04 & 169.0675760 \\
\hline 2 & 10 & 3 & 90 & 1737.26 & 24.30 & 27 & 0.03704 & 10.19 & 59.0089313 \\
\hline 3 & 10 & 9 & 90 & 1801.22 & 72.90 & 81 & 0.01235 & 9.20 & 18.4124711 \\
\hline 4 & 10 & 27 & 90 & 1808.93 & 218.70 & 243 & 0.00412 & 9.28 & 6.2173594 \\
\hline 5 & 10 & 81 & 90 & 1682.32 & 656.10 & 729 & 0.00137 & 8.75 & 1.8173210 \\
\hline 6 & 10 & 243 & 90 & 1666.35 & 1968.30 & 2187 & 0.00046 & 14.78 & 1.0135246 \\
\hline 7 & 20 & 1 & 80 & 1750.16 & 3.20 & 4 & 0.25000 & 20.17 & 353.0072720 \\
\hline 8 & 20 & 3 & 80 & 1793.90 & 9.60 & 12 & 0.08333 & 20.23 & 120.9686567 \\
\hline 9 & 20 & 9 & 80 & 1914.29 & 28.80 & 36 & 0.02778 & 21.06 & 44.7943860 \\
\hline 10 & 20 & 27 & 80 & 1972.89 & 86.40 & 108 & 0.00926 & 18.70 & 13.6640900 \\
\hline 11 & 20 & 81 & 80 & 1929.83 & 259.20 & 324 & 0.00309 & 18.06 & 4.3028061 \\
\hline 12 & 20 & 243 & 80 & 1666.35 & 777.60 & 972 & 0.00103 & 20.85 & 1.4297694 \\
\hline 13 & 30 & 1 & 70 & 1865.32 & 1.63 & 2.3 & 0.42857 & 30.23 & 563.8862360 \\
\hline 14 & 30 & 3 & 70 & 1892.27 & 4.90 & 7 & 0.14286 & 30.87 & 194.7145830 \\
\hline 15 & 30 & 9 & 70 & 2027.49 & 14.70 & 21 & 0.04762 & 31.09 & 70.0385157 \\
\hline 16 & 30 & 27 & 70 & 2054.09 & 44.10 & 63 & 0.01587 & 26.63 & 20.2594136 \\
\hline 17 & 30 & 81 & 70 & 2214.97 & 132.30 & 189 & 0.00529 & 25.92 & 7.0879040 \\
\hline 18 & 30 & 243 & 70 & 1860.62 & 396.90 & 567 & 0.00176 & 23.19 & 1.7756287 \\
\hline
\end{tabular}

$$
\tau=T_{\text {out }} / M T T R
$$

Literature distinguishes three types of availability: inherent, operational and achieved.

Inherent availability $\left(\eta_{T I}\right)$ is understood as availability of a system with respect only to operating time and corrective maintenance. Parameter $\eta_{T I}$ is equal to $\eta_{T}$, given as Equation (5). It does not include standby and delay times and mean logistics delay time (MLDT) [34].

Achieved availability $\left(\eta_{T A}\right)$ is understood as availability of a system with respect to operating time and both corrective and preventive maintenance (unitless parameter). It ignores mean logistics delay time (MLDT) and may be calculated according to Equation (9) in [min], where MTBM [31] is mean time between maintenance in [min] and $M M T$ is mean maintenance time in [min] [35]. MMT is a measure of maintainability duration preventive and corrective maintenance are taken into account. It is calculated by adding the preventive and corrective maintenance time and dividing it by the number of scheduled and unscheduled maintenance operations during a stated period [36].

$$
\eta_{T A}=M T B M /(M T B M+M T T)
$$

Operational availability $\left(\eta_{T O}\right)$ is differentiated from achieved availability by the fact it includes mean logistics delay time (MLDT). MLDT is the indicator of an average time a system is awaiting maintenance and generally includes time for locating parts and tools; locating, setting up or calibrating test equipment; dispatching personnel; reviewing technical manuals; complying with supply procedures; and awaiting transportation [37]. Operation availability (unitless parameter) may be calculated according to Equation (10) [38].

$$
\eta_{T O}=M T B M /(M T B M+M T T+M L D T)
$$

The entire simulation model is predefined, verified and realistic thanks to usage of PRGN of two kinds: the predefined in simulation software and the one prepared by paper's first author - specifications of them are given in the paper. The software predefined PRGN includes MLDT (it was assumed that MLDT is a result of PRGN implementation), therefore instead of computing operation availability, in this paper inherent availability is computed.

\section{Results discussion}

Results of $k$ experiments on the model are gathered in Table 1 and Table 2. Experiments allowed to obtain several facts connected to availability, based on values given in Table 1:

- $\quad$ with the increase of $\operatorname{MTTR}(k)$ ( $\eta_{T}=$ const) values of operating time oscillate similarly as mean values of $\mathrm{OP}$ times given in Figures 1-3;

- $\quad$ with the increase of $\operatorname{MTTR}(k)$ ( $\left.\eta_{T}=\mathrm{const}\right), \operatorname{MTTF}(k)$ and $M T B F(k)$ increase exponentially (Figures 4-6) 
Table 2 Usage of AS/RS, where: mean value of OP process time $\overline{t(k, P S)}$, standard deviation, $s_{t(k, P S)}$ and mean squared error of the mean value $s \overline{t(k, P S)}$

\begin{tabular}{|c|c|c|c|c|c|c|c|c|c|c|c|c|c|}
\hline \multirow[b]{2}{*}{$k$} & \multicolumn{2}{|c|}{ Operational } & \multirow[b]{2}{*}{$\begin{array}{c}\text { Failed } \\
{[\%]}\end{array}$} & \multirow[b]{2}{*}{$\begin{array}{c}\overline{t(k, P S)} \\
{[\mathrm{min}]}\end{array}$} & \multirow[b]{2}{*}{$\begin{array}{c}S_{t(k, P S)} \\
{[\mathrm{min}]}\end{array}$} & \multirow[b]{2}{*}{$\begin{array}{l}S_{\overline{(t, P S)}} \\
{[\mathrm{min}]}\end{array}$} & \multirow[b]{2}{*}{$k$} & \multicolumn{2}{|c|}{ Operational } & \multirow[b]{2}{*}{$\begin{array}{c}\text { Failed } \\
{[\%]}\end{array}$} & \multirow[b]{2}{*}{$\begin{array}{c}\overline{t(k, P S)} \\
{[\mathrm{min}]}\end{array}$} & \multirow[b]{2}{*}{$\begin{array}{c}S_{t(k, P S)} \\
{[\mathrm{min}]}\end{array}$} & \multirow[b]{2}{*}{$\begin{array}{l}S \overline{t(k, P S)} \\
{[\mathrm{min}]}\end{array}$} \\
\hline & $\begin{array}{c}\text { Working } \\
{[\%]}\end{array}$ & $\begin{array}{c}\text { Waiting } \\
{[\%]}\end{array}$ & & & & & & $\begin{array}{c}\text { Working } \\
{[\%]}\end{array}$ & $\begin{array}{c}\text { Waiting } \\
{[\%]}\end{array}$ & & & & \\
\hline 1 & 77.54 & 12.42 & 10.04 & 16.84 & 0.94 & 0.09 & 10 & 63.28 & 18.02 & 18.70 & 19.73 & 1.16 & 0.12 \\
\hline 2 & 78.75 & 11.06 & 10.19 & 17.37 & 1.07 & 0.11 & 11 & 65.00 & 16.94 & 18.06 & 19.30 & 1.73 & 0.17 \\
\hline 3 & 80.19 & 10.61 & 9.20 & 18.01 & 1.01 & 0.10 & 12 & 58.13 & 21.02 & 20.85 & 16.66 & 0.98 & 0.10 \\
\hline 4 & 76.25 & 14.47 & 9.28 & 18.09 & 0.77 & 0.08 & 13 & 47.12 & 22.65 & 30.23 & 18.65 & 0.53 & 0.05 \\
\hline 5 & 81.96 & 9.29 & 8.75 & 16.82 & 0.95 & 0.10 & 14 & 46.33 & 22.80 & 30.87 & 18.92 & 1.47 & 0.15 \\
\hline 6 & 67.74 & 17.48 & 14.78 & 16.66 & 0.98 & 0.10 & 15 & 45.63 & 23.28 & 31.09 & 20.27 & 2.15 & 0.22 \\
\hline 7 & 62.38 & 17.45 & 20.17 & 17.50 & 0.79 & 0.08 & 16 & 51.07 & 22.30 & 26.63 & 20.54 & 1.80 & 0.18 \\
\hline 8 & 60.51 & 19.26 & 20.23 & 17.93 & 0.77 & 0.08 & 17 & 52.40 & 21.68 & 25.92 & 22.15 & 2.48 & 0.25 \\
\hline 9 & 60.60 & 18.34 & 21.06 & 19.14 & 1.57 & 0.16 & 18 & 55.40 & 21.41 & 23.19 & 18.61 & 2.49 & 0.25 \\
\hline
\end{tabular}

Table 3 Comparison of MTTF and FTOF (in relation to operating time)

\begin{tabular}{ccccccccc}
\hline$k$ & $\begin{array}{c}M T T F(k) \\
{[\mathrm{min}]}\end{array}$ & $\begin{array}{c}F T O F(k) \\
{[\mathrm{min}]}\end{array}$ & $k$ & $\begin{array}{c}\text { MTTF }(k) \\
{[\mathrm{min}]}\end{array}$ & $\begin{array}{c}F T O F(k) \\
{[\mathrm{min}]}\end{array}$ & $k$ & $\begin{array}{c}M T T F(k) \\
{[\mathrm{min}]}\end{array}$ & $\begin{array}{c}F T O F(k) \\
{[\mathrm{min}]}\end{array}$ \\
\hline 1 & 8.10 & 14.90 & 7 & 3.20 & 138.33 & 13 & 1.63 & 4.25 \\
2 & 24.30 & 42.20 & 8 & 9.60 & 41.50 & 14 & 4.90 & 24.90 \\
3 & 72.90 & 179.10 & 9 & 28.80 & 220.40 & 15 & 14.70 & 47.56 \\
4 & 218.70 & 413.80 & 10 & 86.40 & 379.10 & 16 & 44.10 & 95.10 \\
5 & 656.10 & 1180.90 & 11 & 259.20 & 1283.43 & 17 & 132.30 & 275.00 \\
6 & 1968.30 & $*$ & 12 & 777.60 & $*$ & 18 & 396.90 & 1205.70 \\
\hline
\end{tabular}

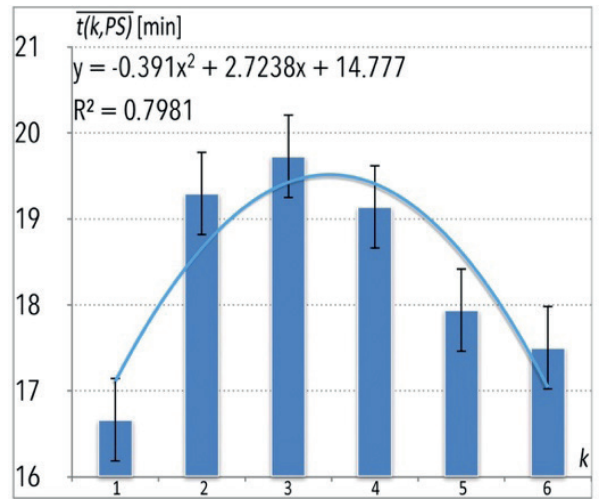

Figure 1 Mean value of OP process time that accrue on the experiments $k=\{1, \ldots, 6\}$

which confirms the theory and confirms that the simulation model was verified accordingly;

- $10 \%$ reduction in availability results in a halving of $\operatorname{MTTF}(k)$ and $M T B F(k)$ values (Figures 4-6);

- $\quad$ with the increase of $\operatorname{MTTR}(k)$ ( $\eta_{T}=$ const), failure rate $\mu(k)$ and failure frequency $\tau(k)$ decrease exponentially, proportional to values of $\operatorname{MTTF}(k)$ and $\operatorname{MTBF}(k)$, Figures 7-8;

- failure rate $\mu(k)$ and failure frequency $\tau(k)$ decrease with reduction of availability $\eta_{T}$;

- $\quad$ as it was mentioned before, MTBF is a little bit longer than MTTF - this research proved the theory; and the difference between $M T B F(k)$ and $\operatorname{MTTF}(k)$ is equal to

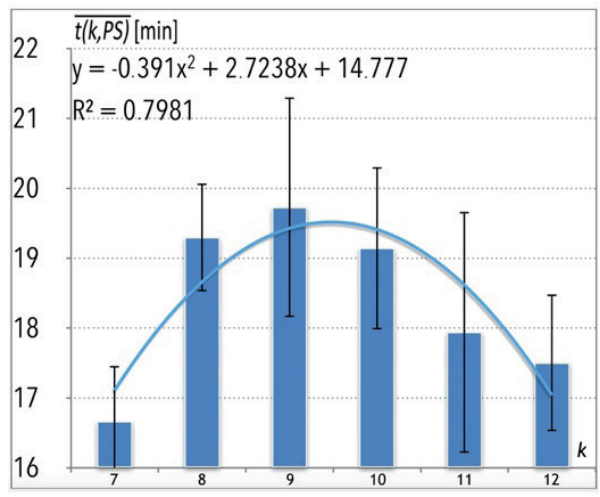

Figure 2 Mean value of OP process time that accrue on the experiments $k=\{7, \ldots, 12\}$

c.a. MTTR(k) (MTBF can be understood as a sum of MTTF and MTTR);

- the Figures 1-3 show the duration of OP process obtained for 18 simulation experiments - the values of OP process time are given as average values from 100-elements samples (100 runs of the simulation model). Figures 1-3 show that the duration of $\mathrm{OP}$ process does not increase while MTTR increasing, however changes of durations for consecutive experiments can be described by second-degree polynomial functions with determination coefficient, each given in consecutive figure, for every next experiment. Nevertheless, increasing of $f(k)$ parameter and decreasing of availability $\eta_{T}$ make OP process 


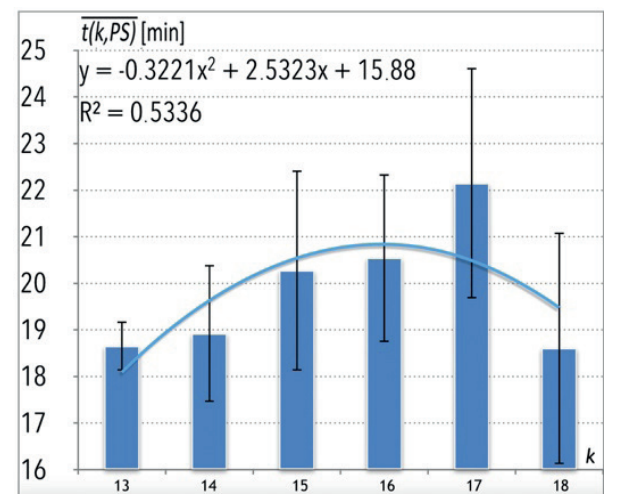

Figure 3 Mean value of $O P$ process time that accrue on the experiments $k=\{13, \ldots, 18\}$

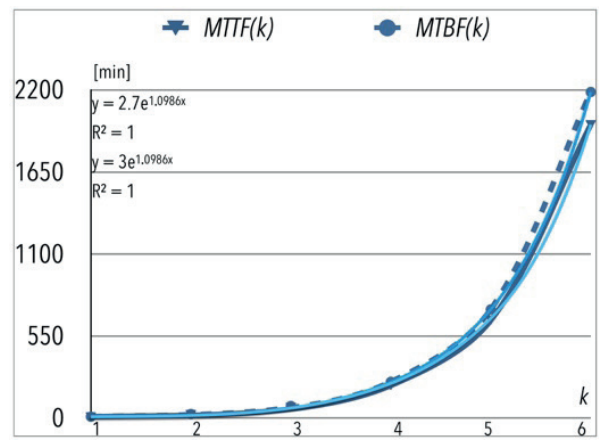

Figure 4 Comparison of MTTF and MTBF that accrue on the experiments $k=\{1, \ldots, 6\}$

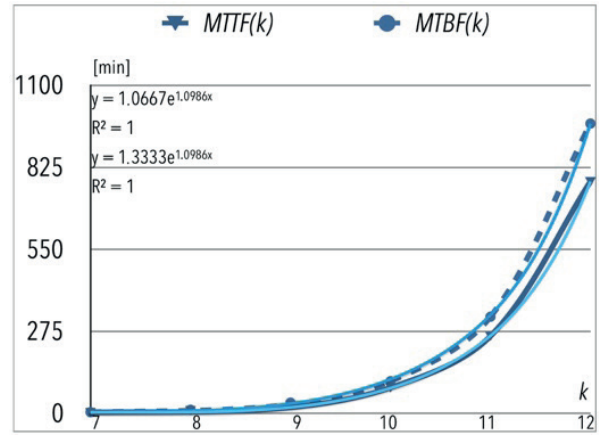

Figure 5 Comparison of MTTF and MTBF that accrue on the experiments $k=\{7, \ldots, 12\}$

times longer what was expected. In all three cases of $f(k)$, the best approximation turns out to be the polynomial of the second degree. All trend diagrams are plotted within the limits range of the standard deviation accompanying the bars of the average duration of OP processes for the individual experiments with consecutive numbers of $k$;

- MTBF should be as short as possible and it is an overall indicator of reliability and effectiveness/efficiency, therefore MTTR should be as short as possible.

Comparison of MTTF and first time of failure FTOF is given in Table 3. In the case of records with asterisks, the failure did not occur during the experiment; after two days of operation time the simulations were interrupted.

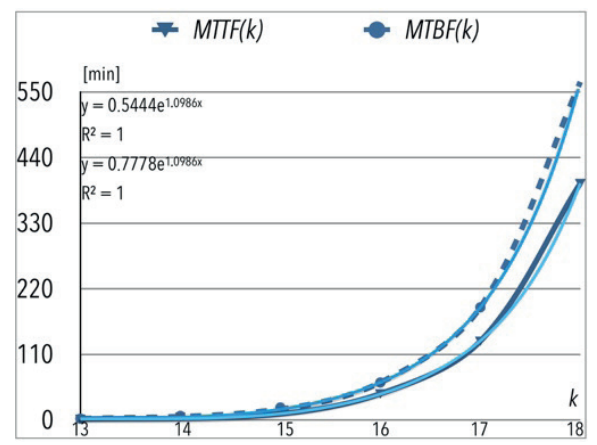

Figure 6 Comparison of MTTF and MTBF that accrue on the experiments $k=\{13, \ldots, 18\}$

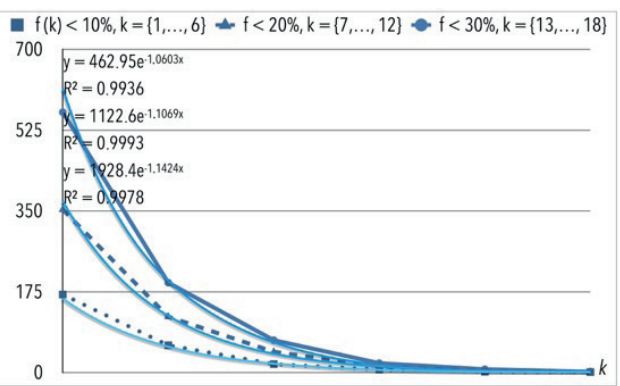

Figure 7 Changes of failure frequency $\tau(k)$ that accrue on the experiments $k=\{1, \ldots, 18\}$

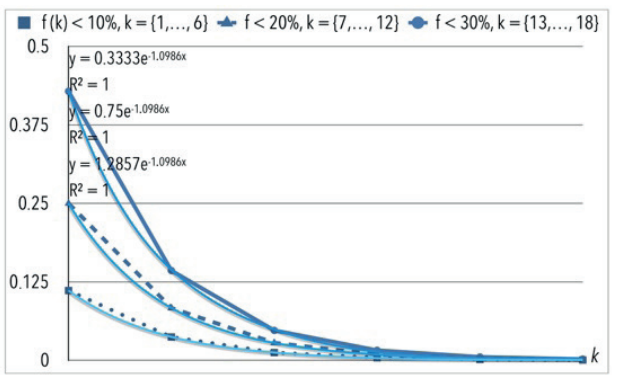

Figure 8 Changes of failure rate $\mu(k)$ that accrue on the experiments $k=\{1, \ldots, 18\}$

\section{Conclusion}

Availability analysis allows to determine when a machine should be replaced or when a machine should be passed for technical inspection. In such cases, each component of a machine would have to be treated separately and not as a whole. For key machines the following principle is generally adopted: preventive replacement of parts every 85\% MTBF [39]. This can be understood that a device should be inspected after this time. At current stage of the model, it can only be concluded that some unspecified failures may occur. It is worth noting that in the model, it is not so much the device's interference analysis that is important, but the process of internal transport and OP technologies. With this assumption, the model is fully functional, and the analyses are satisfactory. 
In the introduction section of the paper research question was given: can the mean time to failure, calculated from the generalized mean time to failure equation, be treated as the value of time when the first failure in the model occurs? Based on the data obtained during computation with the model, the answer is "no", because of difference in pair of values $\operatorname{MTTF}(k)$ and $F T O F(k)$ given in Table 3. However, after computing Pearson correlation coefficient for MTTF and FTOF, the value of the coefficient is 0.88 , therefore the correlation is strong and positive (two pairs of values were excluded, $k=\{6,12\}$ - in their case any failure did not occur during the experiment; after 2 days of operation time the simulations were stopped). The FTOF values for each $k$ were obtained from individual experiments - in future studies further experiments will be conducted in order to enrich verification of the research question.

\section{References}

[1] BARTHOLDI, J. J., HACKMAN, S. T. Warehouse \& distribution science. Authors own release 0.97. Atlanta, US: Georgia Institute of Technology, 2016 [online]. [Vieved 2018-06-17]. Available from: www.warehouse-science.com

[2] ULBRICH, A., GALKA, S., GUNTHNER, W. A. Simulation of multi-level order picking systems within rough planning for decision making. In: SCSC '09 Proceedings of the 2009 Summer Computer Simulation Conference: proceedings. Istanbul, Turkey: Society for Modeling and Simulation International, 2009. p. 322-327.

[3] LU, W., MCFARLANE, D., GIANNIKAS, V., ZHANG, Q. An algorithm for dynamic order picking in warehouse operations. European Journal of Operational Research [online]. 2016, 248(1), p. 107-122 [accessed 2019-07-17]. ISSN 0377-2217. Available from: https://doi.org/10.1016/j.ejor.2015.06.074

[4] ROODBERGEN, K. J., KOSTER, R. DE. Routing order pickers in a warehouse with a middle aisle. European Journal of Operational Research [online]. 2001, 133(1), p. 32-43 [accessed 2019-07-87]. ISSN 0377-2217. Available from: https://doi.org/10.1016/S0377-2217(00)00177-6

[5] CHIANG, D. M.-H., LIN, C.-P., CHEN, M.-C. The adaptive approach for storage assignment by mining data of warehouse management system for distribution centres. Enterprise Information Systems [online]. 2011, 5(2), p. 219-234 [accessed 2019-07-17]. ISSN 1751-7583. Available from: https://doi.org/10.1080/17517575.2010.537784

[6] DRURY, J. Towards more efficient order picking. 2. ed. IMM Monograph No. 1, Report. Cranfield, U. K.: The Institute of Materials Management, 1988. ISBN 9781870214063.

[7] KOSTRZEWSKI, M. Mathematical models of time computing in two-dimensional order picking process in highbay warehouses. In: Quantitative Methods in Logistics Management. Krakow, Poland: AGH Press, 2014, p. 55-69. ISBN 978-83-7464-713-7

[8] GALAZKA, M., JAKUBIAK, M. Simulation as a method of choosing the order picking concept. Logistics and Transport [online]. 2010, 2(11), 2010, p. 81-88 [accessed 2019-07-17]. ISSN 1734-2015. Available from: https://bit.ly/2Z11j44

[9] KRAJCOVIC, M., GABAJOVA, G., MICIETA, B. Order picking using augmented reality. Communications Scientific Letters of the University of Zilina [online].2014, 16(3A), 106-111 [accessed 2019-07-17]. ISSN 1338-9777, eISSN 2585-7878. Available from: http://komunikacie.uniza.sk/index.php/communications/article/view/552/517

[10] QUADER, S., CASTILLO-VILLAR, K. K. Design of an enhanced multi-aisle order picking system considering storage assignments and routing heuristics. Robotics and Computer-Integrated Manufacturing [online]. 2018, 50, p. 1-17 [accessed 2019-07-18]. ISSN 0736-5845. Available from: https://doi.org/10.1016/j.rcim.2015.12.009

[11] PAN, J. CH.-H., SHIH, P.-H., WU, M.-H. Storage assignment problem with travel distance and blocking considerations for a picker-to-part order picking system. Computers and Industrial Engineering [online]. 2012, 62(2), p. 527-535 [accessed 2019-07-18]. ISSN 0360-8352. Available from: https://doi.org/10.1016/j.cie.2011.11.001

[12] VENKITASUBRAMONY, R., ADIL, G. K. Design of an order picking warehouse factoring vertical travel and space sharing. The International Journal of Advanced Manufacturing Technology [online]. 2017, 91(5-8), p. 1921-1934 [accessed 2019-07-18]. ISSN 1433-3015. Available from: https://doi.org/10.1007/s00170-016-9879-3

[13] DAVARZANI, H., NORRMAN, A. Toward a relevant agenda for warehousing research: literature review and practitioners' input. Logistics Research [online]. 2015, 8(1), p. 1-18 [accessed 2019-07-17]. ISSN 1865-035X. Available from: https://doi.org/10.1007/s12159-014-0120-1

[14] TAYLOR-SAKYI, K. Reliability testing strategy. reliability in software engineering [online]. 2016, p. 1-11 [accessed 2019 07-22]. Available from: https://bit.ly/2MWVBOw

[15] BANGSOW, S. Manufacturing Simulation with Plant Simulation and SimTalk. Usage and Programming with Examples and Solutions. Berlin Heidelberg: Springer-Verlag, 2010. ISBN 9783642050732.

[16] MUSA, J. D. Software reliability engineering: more reliable software faster and cheaper. 2. ed. Bloomington, Indiana: AuthorHouse, 2004. ISBN 9781418493882.

[17] KOSTRZEWSKI, M. Modelowanie i badanie wybranych elementow i obiektow logistycznych z wykorzystaniem metod symulacyjnych / Modeling and research on selected elements and full logistics facilities with the use of simulation methods (in Polish). Warsaw, Poland: Oficyna Wydawnicza Politechniki Warszawskiej, 2018. ISBN 9788378147503 
[18] SEMENOV, I. N., FILINA-DAWIDOWICZ, L. Topology-based approach to the modernization of transport and logistics systems with hybrid architecture. Part 1. Proof-of-concept study. Archives of Transport [online]. 2017, 43(3), p. 105-124 [accessed 2019-08-12]. ISSN 0866-9546. Available from: https://doi.org/10.5604/01.3001.0010.4229

[19] MICHLOWICZ, E., KARWAT, B. Implementation of total productive maintenance - TPM in an enterprise. Scientific Journals Maritime University of Szczecin [online]. 2010, 24(96), p. 41-47 [accessed 2019-07-18]. ISSN 1733-8670. Available from: https://bit.ly/2KKUpeb

[20] WAKIRU, J. et al. Maintenance optimization: application of remanufacturing and repair strategies. Procedia CIRP [online]. 2018, 69, p. 899-904, ISSN 2212-8271. Available from: https://doi.org/10.1016/j.procir.2017.11.008

[21] SADOK, T., NIDHAL, R. Study of a manufacturing system with transport activities in urban area. IFACPapersOnLine [online]. 2016, 49(3), p. 419-423 [accessed 2019-07-24]. ISSN 2405-8963. Available from: https://doi.org/10.1016/j.ifacol.2016.07.070

[22] KUKULKA, A., WIRKUS, M. Issues of measuring the course of batch production processes. Procedia Engineering [online]. 2017, 182, p. 387-395 [accessed 2019-07-24]. ISSN 1877-7058. Available from: https://doi.org/10.1016/j.proeng.2017.03.119

[23] FUSKO, M., RAKYTA, M., MANLIG, F. Reducing of intralogistics costs of spare parts and material of implementation digitization in maintenance. Procedia Engineering [online]. 2017, 192, p. 213-218 [accessed 2019-07-24]. ISSN 1877-7058. Available from: https://doi.org/10.1016/j.proeng.2017.06.037

[24] YAN, CH.-B., ZHAO, Q., HUANG, N., XIAO, G., LI, J. Line-side buffer assignment in general assembly line systems with material handling. IFAC Proceedings Volumes [online]. 2009, 42(4), p. 1256-1261 [accessed 2019-07-24]. ISSN 1474-6670. Available from: https://doi.org/10.3182/20090603-3-RU-2001.0310

[25] BUKOWSKI, L. A. Zapewnienie ciaglosci dostaw w zmiennym i niepewnym otoczeniu / Ensuring continuity of supplies in a changing and uncertain environment (in Polish). Dabrowa Gornicza: Wydawnictwo Naukowe Wyzsza Szkola Biznesu w Dabrowie Gorniczej, 2016. ISBN 9788364927508.

[26] LESZCZYNSKI, J. Modelowanie systemow i procesow transportowych / Modeling of transport systems and processes (in Polish). Warszawa: Oficyna Wydawnicza Politechniki Warszawskiej, 1999. ISBN 8386569093.

[27] GUTENBAUM, J. Modelowanie matematyczne systemow / Mathematical modelling of systems (in Polish). 3. ed. Warsaw, Poland: Akademicka Oficyna Wydawnicza EXIT, 2003. ISBN 8387674532.

[28] KOSTRZEWSKI, M. Comparison of the order picking processes duration based on data obtained from the use of pseudorandom number generator. Transportation Research Procedia. 2019, 40, p. 317-324 [accessed 2019-08-12]. ISSN 2352-1465. Available from: https://doi.org/10.1016/j.trpro.2019.07.047

[29] FEDERATION EUROPEENNE DE LA MANUTENTION. Performance data of S/R-machines. Reliability. Availability. 1. ed. FEM 9.221. Frankfort: Germany, 2001.

[30] TRIVEDI, K. BOBBIO, A. Reliability and availability engineering: modeling, analysis and applications. Cambridge: Cambridge University Press, 2017. ISBN 9781316163047.

[31] STANLEY, S. MTBF, MTTR, MTTF and FIT explanation of terms [online]. [Viewed 2019-07-22]. Available from: https://bit.ly/2rBavBz

[32] RHEE, S. J., ISHII, K. Using cost based FMEA to enhance reliability and serviceability. Advanced Engineering Informatics [online]. 2003, 17(3-4), p. 179-188 [accessed 2019-07-17]. ISSN 1474-0346. Available from: https://doi.org/10.1016/j.aei.2004.07.002

[33] BIROLINI, A. Reliability Engineering [online]. Berlin Heidelberg: Springer-Verlag, 2017. ISBN 978-3-662-54208-8.

[34] Inherent availability - Glossary of Defense Acquisition [online]. [Viewed 2019-07-23]. Available from: https://bit.ly/31wvr9p

[35] Achieved availability - Glossary of Defense Acquisition [online]. [Viewed 2019-07-23]. Available from: https://bit.ly/33mH018

[36] MMT - Glossary of Defense Acquisition [online]. [Viewed 2019-07-22]. Available from: https://bit.ly/2Me1Xte

[37] MLDT - Glossary of Defense Acquisition [online]. [Viewed 2019-07-23]. Available from: https://bit.ly/2YZLH0X

[38] Operation availability - Glossary of Defense Acquisition [online]. [Viewed 2019-07-23]. Available from: https://bit.ly/2KIrgk4

[39] MISIUREK, B. MTBF, MTTR i MTTF - jak i po co stosowac te wskazniki? / MTBF, MTTR and MTTF - how and why use these indicators? (in Polish). Sluzby Utrzymania Ruchu. 2017, 1. ISSN 1896-0677. 